\title{
CANDIDATES FOR THE LEADERSHIP
}

\section{Officers, Councillors on the ballot}

Vice presidents of the Materials Research Society, and five members of the 15 -member governing council, will be elected in balloting being carried out through this issue of the Bulletin.

Again this year, we are using the newsletter to carry out the election because it can convey information about the candidates as well as print the ballot. We must repeat, therefore, that this is the only election material you will receive. Please read this issue carefully before marking your ballot and returning it to the Society's Secretariat.

\section{Offices to be Filled}

According to MRS by-laws, the Society's president is not elected directly; rather the First Vice President automatically assumes the presidency at the end of his or her one-year term. Thus the highest office to be filled in this election is that of First Vice President.

Slated for the First Vice Presidency for 1984 by the Society's Nominating Committee is Elton N. Kaufmann of Lawrence Livermore National Laboratory, this year's Second Vice President. Long active in the MRS's leadership, Elton's present service has been outstanding and he is unopposed for the position. However, space has been provided on the Official Ballot for

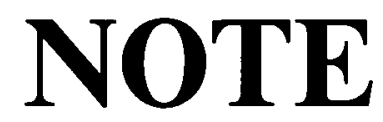

In this issue of the Bulletin you will find information about the candidates for election to the Society's leadership. Also published within is the Official Ballot.

This is the only ballot you will receive.

Evaluate the candidates and vote your ballot according to the instructions that accompany it.

Return the ballot by Aug. 31 to Ernest Hawk, Executive Secretary, MRS, 110 Materials Research Laboratory, University Park, PA 16802.

This is the only notice of election you will receive. Please don't fail to vote.

write ins.

The other office filled every year is that of Second Vice President. In a departure from past practice - and evidence of the Society's growth and diversity - the Nominating Committee is putting forward the names of two of its most committed and talented workers, rather than slating a single candidate. They are Gordon E. Pike of Sandia National Laboratories and Bill R. Appleton of Oak Ridge National Laboratory. Each has capped a succession of services to the Society by serving as co-chairman of this year's Annual Meeting in Boston, along with Bernard H. Kear of Exxon.

Similarly, the Nominating Committee has offered the names of nine energetic materials scientists for consideration to fill five vacancies on the Society's governing council. Each year a third of the council's 15 members are elected. They are profiled in the following pages.

Election Rules

One vote may be cast for each of the officer positions to be filled. In the case of council members, a ranking system is used to eliminate the possibility of ties. The candidates are presented in an order determined by random number selection. Each is to be ranked from one to nine with no "tie" numbers

[Continued on Page 7] 


\section{CANDIDATES FOR THE LEADERSHIP}

\section{[Continued from Page 1]}

and "one" being the most highly ranked.

Ballots must be received no later than Aug. 31 in University Park, PA. Please allow sufficient time for postal delivery.

\section{For 1st Vice President}

\section{ELTON N. KAUFMANN}

Lawrence Livermore National

Laboratory

P.O. Box 808, L-217

Livermore, CA 94550

(415) $423-2640$

Elton Kaufmann joined the Materials Science Division of Lawrence Livermore National Laboratory in 1981. Presently he is studying the application of directed energy processing methods to materials.

Elton earned his BS in 1964 from Rensselaer Polytechnic Institute and completed his Ph.D. in 1968 at the California Institute of Technology. Both degrees are in physics. From 1968 through 1981 he was a member of the technical staff of Bell Laboratories, where he studied materials properties using hyperfine interactions, ion-solid interactions and laser-solid interaction techniques. He is editor of Hyperfine Interactions and two books, and author of more than 80 technical articles. In 1980, he co-chaired the MRS Symposium on Nuclear and Electron Resonance Spectroscopies Applied to Materials Science. In 1982, he cochaired the Annual Meeting in Boston. Presently, he is the Society's Second Vice President.

"The MRS is experiencing rapid growth in several areas," Kaufmann notes. "A new spring meeting in the Western U.S. is in place. A new and expanded Society headquarters is in the offing. The skeleton of an international MRS has been built. Member services have expanded, notably an expansion of

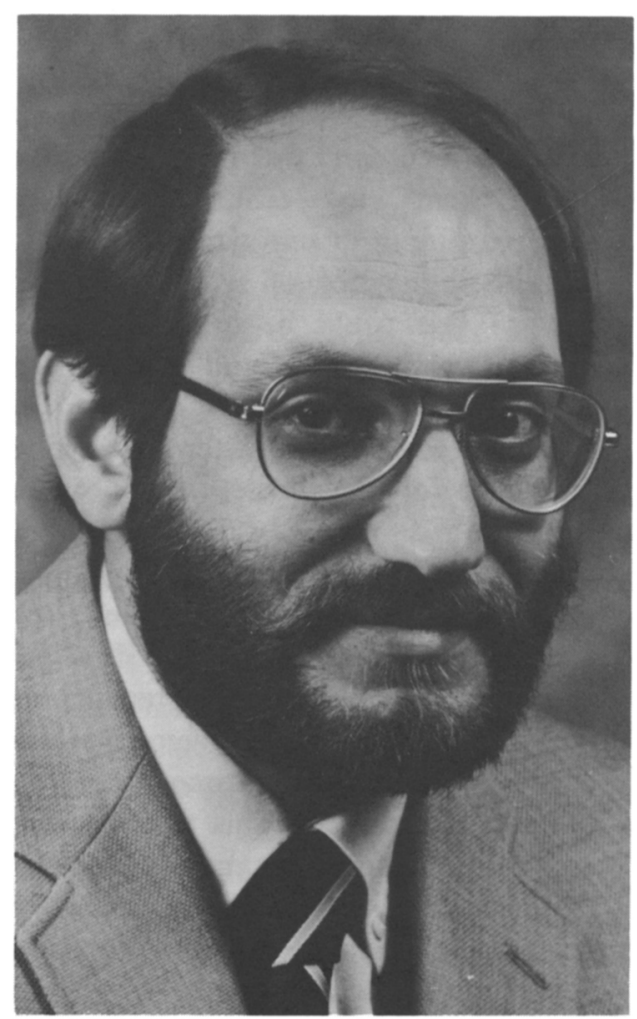

direction of the Society. The challenge now is the maintenance and nurturing of those attributes during the Society's growth as an institution.

"As an officer of the MRS, I regard my primary responsibility as insuring the availability of the appropriate implements and atmosphere to guarantee technically excellent and exciting meetings, while using the Society's resources in the most efficient manner possible. If elected First Vice President, I will continue to pursue that course while helping the MRS grow in areas where the demand warrants."

\section{DON'T}

\section{NEGLECT}

\section{TO VOTE}

the Bulletin and association with the new journal, Materials Letters. Short course offerings have become a standard meeting complement. The ranks of MRS corporate affiliates are swelling. And, soon, equipment exhibits will likely be available to our members and other participants at our meetings. This expansion is a direct response to demand from members and meeting attendees, who clearly feel the MRS is playing a valuable role in their participation in the materials research community.

"I attribute this success both to the interdisciplinary nature of our forums, which so well emulates the way materials science is pursued in the real world, and to the flexible and innovative methods of meeting and program formulation, which have allowed rapid response to changing research emphasis and opportunities for individual initiative in shaping the
For 2nd Vice President

GORDON E. PIKE

Sandia National Laboratories

Division 1815

Albuquerque, NM 87185

(505) 844-9168

Gordon was graduated from Carnegie Mellon University in 1963 with a B.S. in physics. He received his Ph.D. in solid state physics from the University of Pittsburgh in 1969. That year he joined Sandia National Laboratories, where he has worked in the general area of electrical properties of materials. He has made experimental and theoretical contributions in the fields of electronic hopping transport in insulators, superconductivity, radiation

\section{[Continued on Page 8]}

